\title{
A crítica de Siegried Kracauer AO ROMANCE-REPORTAGEM - OU O "CASO BRECHT"*
}

\author{
Siegfried Kracauer's critique of novel-report \\ or the "Brecht case"
}

RESUMO O presente artigo pretende contextualizar historicamente a posição estético-política de Kracauer diante deste gênero literário que obteve sucesso entre os escritores alemães no início dos anos 1930, o romance-reportagem. A referência à revista berlinense, Die Linkskurve, e à critica de Lukács desenvolvida no período - quando retoma questões estéticas sobre o romance como gênero literário, numa interpretação marxista, e esboça sua tese sobre o "realismo crítico" - é inevitável. Kracauer escreve uma crítica ao filme Kuhle Wampe, dirigido por S. Dudow, com roteiro de B. Brecht e E. Ottwald e música de $\mathrm{H}$. Eisler, que vai engendrar uma discussão cheia de mal-entendidos, mas extremamente interessante, entre $\mathrm{E}$. Bloch e Kracauer e entre este e Brecht. Ao final, detenho-me sobre o projeto da revista Krise und Kritik que, com ascensão de Hitler, não vingou. PALAVRAS-CHAVE ROMANCE-REPORTAGEM; REVISTA DIE LINKSKURVE; FILME KUHLE WAMPE; KRACAUER, LUKÁCS, BRECHT E BLOCH.

ABSTRACT ThIS ARTICLE SEEKS To historically contextualize Kracauer's aesthetic-political position regarding this successful literary genre among German writers in the early 1930s: the novel report. It is inevitable the reference to the Berlin journal, Die Linkskurve, and to Lukács's critiques developed in the period - when he resumes aesthetic questions on the novel as a literary genre in a Marxist interpretation and outlines his thesis on "critical realism". Kracauer wrote a critique about the film Kuhle Wampe, directed by S. Dudow with a script by B. Brecht and E. Ottwald and music by $\mathrm{H}$. Eisler, which engendered a discussion full of misunderstandings, but extremely interesting, between E. Bloch and Kracauer and between Kracauer and Brecht. Finally, I comment the journal project Krise und Kritik, which failed with the rise of Hitler.

KeYWORDS NOVEL-REPORT; DIE LINKSKURVE; KUHLE WAMPE; KRACAUER; LUKÁCS; BRECHT; BLOCH.

* O capítulo foi publicado em MACHADO, C. E. J.; VEDDA, M., 2010. A versão aqui foi ampliada.

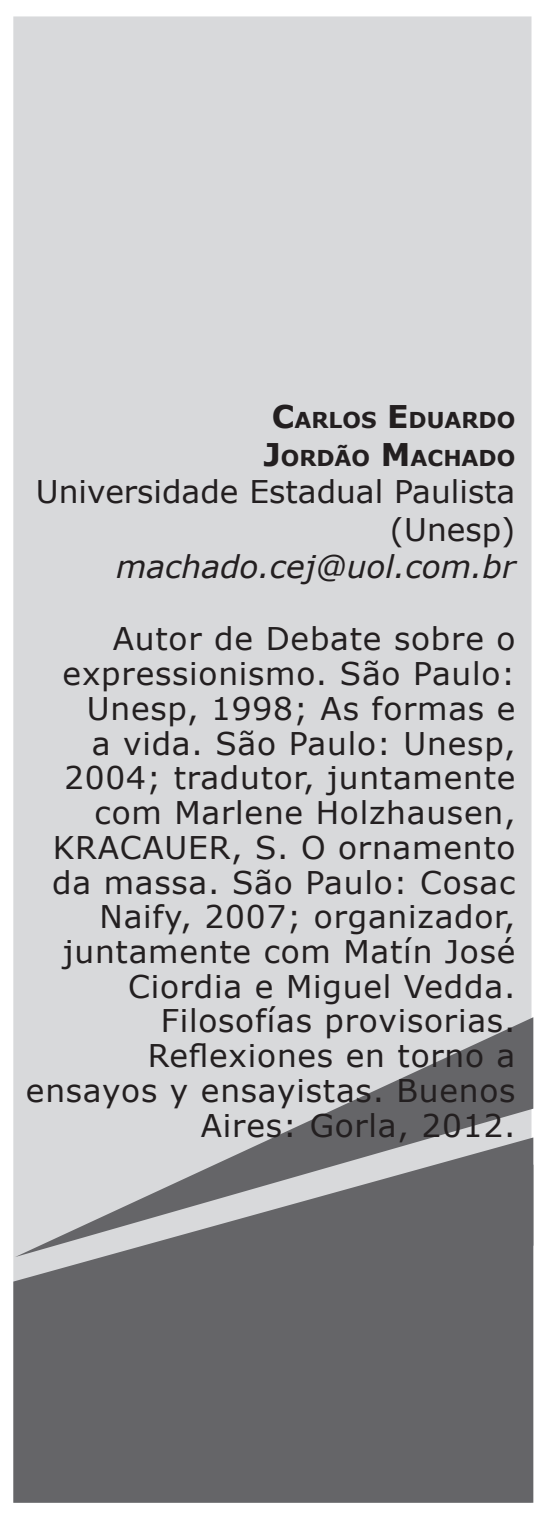




\section{INTRODUÇÃO}

$\mathrm{N}$

o capítulo introdutório a Die Angestellten [Os empregados], Kracauer indaga se a realidade que pretende investigar poderia ser captada por meio da reportagem comum:

De alguns anos para cá a reportagem desfruta, na Alemanha, um lugar preferencial entre todas as formas de exposição, pois somente ela - diz-se - pode apoderar-se da vida em toda sua fluidez. Os escritores não conhecem praticamente uma ambição maior que a de informar; a reprodução do observado é o triunfo, o que justamente conta. (KRACAUER, 1971, p. 15).

Como reação ao idealismo desbotado e desnutrido é, segundo ele, uma reação justificada, mas não mais do que isto. "Cem informes sobre uma fábrica não podem ser somados até construir a realidade da fábrica, senão que seguem sendo, eternamente, cem modos de ver a fábrica" (Ibid, p. 15). Sua posição é sutil, não se trata nem da abstratividade de conceitos que não dão conta da realidade, tampouco do registro do imediato da mera empiria, do factual. E acrescenta em uma frase programática: "A realidade é uma construção. Certamente a vida deve ser observada a fim de que a realidade se apresente na exposição" (Ibid., p. 15). E aproxima a reportagem da fotografia, nos mesmos termos de seu ensaio pioneiro de 1927, quando compara o registro fotográfico ao método do historicismo, ao tentar "fazer uma fotografia do tempo" (1977, p. 24). ${ }^{1}$ O resultado seria um mosaico de partes desconectadas sem visão do todo, uma mera somatória de partes desconexas. ${ }^{2}$ Essa forma de escrita chegou

Edição brasileira: O ornamento da massa. Trad. Carlos Eduardo J. Machado e Marlene Holzhausen. São Paulo: Cosac Naify, 2009.

2 Sem refutar a montagem como método de configuração artística, sobretudo no cinema, no qual é inimaginável sem a montagem, vendo nos soviéticos os mestres no uso deste método. No entanto, para Kracauer, o calcanhar de Aquiles do filme de Ruttmann, Berlin, mostra-se justamente neste aspecto: a falta de conexão entre as parte. a obter certa popularidade na ocasião entre os escritores de esquerda. Se Kracauer diferencia concretamente sua forma expositiva, o que define como "literatura sociológica", da mera reportagem, não abrindo mão da apreensão sensível e materialista do "mundo das coisas", é em outro ensaio escrito em junho de 1932, em que se posiciona de modo inequívoco diante da "reportagem": "Sobre um romance da confecção. Juntamente com uma digressão sobre o romance de reportagem social"3 (KRACAUER, 1990, p. 75-79).

\section{ROMANCE REPORTAGEM}

Kracauer escreveu uma resenha a propósito do romance de Werner Turk, intitulado Konfektion, já citado, e faz uma digressão crítica sobre o romance-reportagem, que é o mais importante aqui. Para Kracauer, Turk tem a qualidade de elaborar literariamente um âmbito da realidade de Berlim que, todavia, ainda não havia sido objeto de configuração. Tem a vantagem de não colocar em cena "manequins", mas personagens vivos, diferenciando daqueles nos quais o plano de fundo permanece sendo mero plano de fundo da narrativa, por exemplo, alguns romances que enfocam a guerra como mero pretexto para uma historieta de amor etc. Assim, configura uma constelação de personagens: o chefe e seus intermediários, o viajante, os aprendizes, os servidores que não são narrados de fora, meramente do exterior, mas dentro mesmo de seu âmbito de ação, construindo uma topografia viva com sua linguagem e hábitos próprios que dominam este mundo que é narrado, possibilitando uma aprendizagem ao leitor. Sua tendência é radical sem ser um romance-reportagem social de tendência. Neste ponto Kracauer explicita melhor sua posição.

Segundo Kracauer: "A descrição de situações sociais críticas adornadas na forma de romance, que tem dominado entre nós nos últimos anos, é uma forma mista infrutífera (unfruchtbare Mischform)" - grifos do autor (Ibid., p. 76). Pois, além de não adentrar

\footnotetext{
3 "Zu einem Roman aus der Konfektion. Nebst einem Exkurs über die soziale Romanreportage."
} 
apropriadamente nas situações que descreve, não corresponde muito menos às exigências do romance enquanto tal. É o que chama de "vivificação da ciência" (Verlebendigung der Wissenschaft). O que significa isto? Para Kracauer, trata-se de uma tentativa vã; diante do descrédito da ciência, acredita ser possível preencher o vazio desta com a vida, ou seja, fazer a mediação da ciência com a "vida". O resultado não pode ser diferente: retira-se a objetividade dos conceitos, por um lado, e a dinâmica da expressão por outro. Em suas palavras: "Populariza-se esta [a ciência] em vez de se educar com ela; esta é atualizada, em vez de apreender conceitualmente a atualidade". Para esses escritores, acrescenta:

a tarefa de analisar nossas relações sociais na forma de ensaios e de obras científicas parece-lhes muito seca, assim configuram seu material preferencialmente na forma de romances. Supondo que esse método seja mais fácil de aplicar e frequentemente mais imaginável; mas esse permanece bem atrás do valor documental e das possibilidades de intervenção autêntica da análise exata. (p. 76).

Ou seja, falha na conceituação e na caracterização literária. Não conquista nenhum território novo, ficando atrás da investigação sistemática. Do ponto de vista literário, o defeito é ainda maior: as tendências e a situação não provêm da "configuração épica" [epischen Gestaltung], mas tornam-se meros exemplos para "vivificação" do material: "a maioria dos [...] romances-reportagem padecem dos defeitos da aparência de concreticidade [Scheinkonkretheit]" (Ibid., p. 76.). Seus homens não são homens realmente dados na e pela experiência vital, mas "bonecos" [Puppen] (p.76). Cita um exemplo de memória, um romance que leu recentemente, no qual o termo "pequeno-burguês" [Kleinbürger] é utilizado e perpassa toda a narrativa. O termo serve para uma caracterização ingênua de um indivíduo qualquer ou de um grupo de pessoas. Certamente a expressão pertence a uma esfera teórica que possui um significado com definição própria. Mas, na narrativa, o "pequeno-burguês" não vem caracterizado como tal, mas o pequeno-burguês é simplesmente pequeno-burguês, ou seja, ele é tendenciosamente [tendenziös] pequeno-burguês. Como Kracauer sintetiza: "o romance-reportagem falha tanto diante da representação dos fatos como das exigências expressivas do romance enquanto forma. Movimenta-se impotente entre ciência e configuração épica, descoberta e documentário" (Ibid., p. 77).

Kracauer tem em mente uma "literatura sociológica”, seus escritos sobre cidade, para não falar de sua crítica de cinema, e, sobretudo, Os empregados são exemplos, mas, para isso ele não oferece nenhuma "receita".

Cabe agora outro parêntese: a polêmica sobre o romance-reportagem na revista berlinense Die Linkskurve.

\section{Discussão NA DIE LINKSKURVE}

Em outubro de 1928 foi constituída a Federação de Escritores Proletário-Revolucionários, ${ }^{4}$ com hegemonia dos comunistas, estando Johannes Bechher à frente. A revista Die Linkskurve ${ }^{5}$ era o órgão oficial da Federação, que durou de agosto de 1929 a novembro-dezembro de 1932, publicando, ainda em fevereiro de 1933, um número de seu boletim Der Oppositionelle Schrifsteller. ${ }^{6}$ Helga Gallas divide a curta trajetória da revista em quatro fases. A primeira, de agosto de 1929 a meados de 1930, caracteriza-se pelo distanciamento em relação aos escritores burgueses de esquerda e a favor dos operários. $\mathrm{Na}$ segunda, de meados de 1930 a setembro de 1931, a direção posiciona-se contra o “obreirismo" da fase anterior e assume a tarefa de elaborar uma teoria literária inspirada em Hegel. Na terceira, de junho de 1931 a meados de 1932, há uma tentativa de harmonização de ambas as tendências. Finalmente, na última

\footnotetext{
Bundproletarisch-revolutionärer Schrifsteller.

Guinada à esquerda
}

O escritor de oposição 
fase, que se estende até dezembro de 1932, há um rechaço das novas técnicas literárias e uma reivindicação da continuidade da tradição literária clássica.7 Aqui nos interessa destacar a participação de Lukács, que ingressa ativamente na revista a partir de junho de 1931, transferindo-se de Moscou para Berlim, sobretudo em relação à sua crítica ao romance-reportagem: Reportage oder Gestaltung? Kritische Bemerkungen anlässlich des Romans von Ottwald, ${ }^{8}$ publicada na revista nos números 7 e 8 de 1932, ${ }^{9}$ mostrando certa proximidade de sua crítica em algumas questões determinadas com os argumentos de Kracauer e vice-versa.

Para Lukács, o romance de Ottwald, Denn sie wissen, was sie tun. Ein deutscher Justiz-Roman ${ }^{10}$ (1931) é representativo de toda uma tendência literária, de um determinado "método de criação" (LUKÁCS, 1990, p. 359). A reportagem aparece como uma alternativa aos meios tradicionais, envelhecidos, burgueses: "Hoje em dia esta direção se encontra amplamente difundida: desde Upton Sinclair e Tretiakov a Ilia Ehrenburg, os mais diversos escritores utilizam esse método. Em certo aspecto Zola era já um de seus antepassados" (Ibid.). Aqui Lukács lança seus argumentos que estarão na base de sua crítica, não só da reportagem, mas da produção

7 Ver a história detalhada da revista: “A Federação de Escritores Proletário-Revolucionários e seu órgão Die Linkskurve" em Gallas (1973, p. 25-56).

8 Reportagem ou configuração. Observações críticas a propósito do romance de Ottwalt

9 Lukács publica na revista um total de sete ensaios: Tendenz oder Pateilichkeit [Tendência ou partidarismo]; Wille BredelsRomane [Os romances de WilleBredel]; Reportage oder Gestaltung [Reportagem ou configuração]; Aus der Not eine Tugend [Da necessidade uma virtude]; Der faschisierte Goethe [O Goethe fasticizado]. Todos eles reunidos e exaustivamente analisados em Klein (1990). Lukács, durante os anos 1920, escreveu esporadicamente sobre estética e literatura (ver LÖWY,1978). Löwy reúne os artigos publicados na Revista Die Rote Fahne, passa a se ocupar intensivamente do tema a partir dos anos 1930. Sobre esse período na história intelectual de Lukács, ver, entre outros, Machado (1998).

10 Então eles sabem o que fazem. Um romance-justiça alemão. de vanguarda em geral, que é a aproximação dessa tendência ao naturalismo, tendo como precursora a literatura de Emil Zola. Já chegamos a analisar os argumentos de Lukács em outra ocasião. ${ }^{11}$ Aqui cabe apenas destacar de que modo os argumentos de Lukács em relação à interpretação da arte - em particular, à questão do significado e ao modo de configuração, Kracauer chamaria de caracterização do indivíduo no romance e no romance-reportagem - estão de acordo com os argumentos de Kracauer. Obviamente, Lukács vê na reportagem uma forma absolutamente justificada e indispensável na publicística

na verdadeira reportagem se representam o caso individual, o fato, numa segunda vivência (Nacherlebbarkeit) completamente sensível, concreta e individualizada [...] Este caso individual representado e eventualmente configurado é aqui apenas um exemplo e ilustração para a conexão geral, apresentada de forma mais ou menos científica mas em todo caso conceitualmente documentada (sobre uma base estatística), e motivada pelo entendimento discursivo. (LUKÁCS, 1990, p. 364).

A reportagem jornalística não pode prescindir da utilização de conceito, sem o qual se torna impossível estabelecer conexões entre o particular e o geral: "A concreção da reportagem como toda reprodução conceitual (científica) só se completa com o descobrimento da exposição conceitual das causas e conexões" (Ibid., p. 365-366.).

A situação muda quando a reportagem passa ter pretensões "artísticas". Pois, segundo Lukács, os métodos científicos e artísticos são distintos, "se excluem mutuamente":

\footnotetext{
1 Ver "Considerações sobre a trajetória políticointelectual de Lukács na década de 1930" (em MACHADO, 1998, p. 21-48).
} 
uma representação "artística" com fins científicos será sempre uma pseudociência como uma pseudoarte, do mesmo modo que uma solução 'científica' das tarefas especificamente artísticas trará como resultado uma pseudociência pelo seu conteúdo e uma pseudoarte no aspecto formal. (Ibid., p. 366).

Além das críticas dirigidas ao parceiro de Brecht no filme Kuhle Wampe, Ottwalt merece nossa atenção por seus comentários em relação à produção literária do escritor soviético, Tretiakov. O calcanhar de Aquiles desse “método de configuração", segundo Lukács, está no modo insuficiente de caracterização dos personagens individuais e seus destinos, ou seja, em sua incapacidade de configurar indivíduos "típicos" em situações igualmente "típicas", conceituação que Lukács passa a adotar em seus argumentos e que constitui um dos pilares de sua teoria literária - a tipicidade. Segundo Lukács:

todos os representantes desse método mostram a mesma indiferença da representação diante o objeto representado. Em Tretiakov, por exemplo, aparece ainda de forma mais acentuada do que em Ottwalt. Tretiakov conta $[. .$.$] em seu último$ romance [Den-Schi-Chua] a vida de um revolucionário chinês na forma de uma autobiografia. Mas o narrador tem entre cinco e seis anos na época em que seu pai, partidário de Sun-Yat-Sem, retorna ao lar e participa na organização da revolução chinesa. O menino pode participar duma reunião. Nela, seu pai faz uma análise das diferentes correntes dentro do Partido Revolucionário e analisa seus fundamentos sociais. (Ibid., p. 379).

Há uma ausência de concatenação das cenas e dos personagens; os detalhes ga- nham autonomia e desfaz-se a unidade entre forma e conteúdo. Acrescenta Lukács: "a maneira de representar não guarda nenhuma relação com o representado" (Ibid.).

\section{KRACAUER, LUKÁCS E O ROMANCE-REPORTAGEM}

À primeira vista pode parecer que estamos forçando a mão ao aproximar os argumentos de Kracauer aos de Lukács ao criticar o romance-reportagem como uma pseudociência e uma pseudoarte, por ser insuficiente conceitualmente e, ao mesmo tempo, incapaz de responder às questões formais do ponto de vista literário. Mas não somos os únicos a fazer isto. Inka Mülder-Bach, em seu livro pioneiro de 1984, Siegfried Kracauer Grenzgänger zwischen Theorie und Literatur. Seine früehen Schriften 1913-1933, mostra que Kracauer, um pouco antes do debate entre Lukács e Ottwalt, já havia formulado uma crítica radical ao romance-reportagem na digressão já citada por nós como uma "forma mista infrutífera", sendo incapaz de responder seja às exigências científicas seja às artísticas. Observa em uma nota:

Apesar das diferentes exigências de
esclarecimento, de visões político-
-literárias e de interpretação da
arte, Lukács e Kracauer concordam
em relação a algumas questões
importantes, particularmente em
relação à questão sobre o signifi-
cado e o modo de configuração do
indivíduo no romance e no roman-
ce-reportagem. Ambos limitam o
"tipicamente poético" do exemplar
na reportagem. (MÜLDER-BACH,
1985, p. 197).

Só que, enquanto Lukács se expressa conceitualmente, Kracauer o faz por meio de exemplos. Na verdade, Kracauer transpõe para as páginas de um jornal de centro-esquerda, o Frankfurter Zeitung , que na ocasião passava por uma crise financeira e de orientação política, uma polêmica que estava ocor- 
rendo entre os escritores de esquerda, dando expressão a um processo próprio e peculiar de radicalização política.

Seus artigos deste período, de véspera da ascensão política do nacional-socialismo, geraram uma sucessão de mal-entendidos; por exemplo, os que escreveu sobre Tretriakov, já citados, e sobre a proibição de Kuhle Wamp, que provocou quase uma ruptura na amizade com Ernst Bloch, conforme podemos acompanhar na correspondência entre ambos.

\section{Crítica a KUHLE Wamp}

Kuhle Wamp oder: wem gehört die Welt?, ${ }^{12}$ filme dirigido pelo búlgaro Slatan Dudow, com roteiro de Bertold Brecht, Ernst Ottwalt, Slatan Dudow e música de Hans Eisler, foi proibido pela censura (Filmprüfstelle) no final de março de 1932 por ofender o presidente da república, a justiça e a Igreja. Posteriormente foi liberado, com muitos cortes, no final de abril do mesmo ano até ser definitivamente proibido em março do ano seguinte. $\mathrm{O}$ artigo de Kracauer é de 5 de abril de 1932.

O artigo é um protesto contra a proibição que tem como alvo um filme dotado de gravidade própria, como a de um outsider: não é mero produto da indústria cinematográfica estabelecida, ${ }^{13}$ mas obra de um pequeno coletivo independente. Kracauer começa considerando que se trata de dois fatos distintos e por isso devem ser também considerados separadamente: o ataque da censura e o fato de o filme ser uma produção independente. O que mais lhe chama atenção de imediato é a decisão insustentável da censura, que dificilmente miraria seu alvo sem mais em uma produção do "mundo de calicó" - os grandes estúdios da UFA. ${ }^{14}$ O filme

12 Barrigas frias ou $A$ quem pertence o mundo?

13 Kracauer faz um balanço da produção cinematográfica estabelecida alemã evidenciando sua falta de substância (Substanklosigkeit) no ensaio já citado “Film 1928" (KRACAUER, S., 1977, p. 295-31).

14 Ver o ensaio (magistral) do início de 1926 e que the causou cada vez mais embaraços entre os chefões da indústria cinematográfica alemã e a direção do Frankfurter Zeitung: "Die Kaliko-Welt. Die Ufa-Stadt zu Neubabelsberg” (KRACAUER, 1977, p. 271-278). retrata as condições de vida entre os desempregados (Arbeitslosen). Dividido em três episódios, tem como ponto central uma família de desocupados (Erwerbslosenfamilie), cujo destino peculiar é ilustrado de maneira geral (allgemeineillustriert). ${ }^{15}$ Os pais possuem uma mentalidade pequeno-burguesa, com dizeres que não dão mais conta da realidade; o pai é repressivo e, após comunicar à família sobre a redução da previdência, provoca o suicídio do filho; a segunda parte passa-se nos arredores de Berlim, em um acampamento dos sem-teto, que dá título ao filme, Kuhle Wamp. Neste ponto, o filme lança uma crítica à visão de filisteu (Speissbürgerlichkeit), à sua resignação diante da vida. A filha do casal infeliz encontra-se grávida de um rapaz que não tem onde cair morto, contrastando com a relativa abundância de comida e bebida na festa de noivado cheia de bebedeira, mostrando o mundo pequeno-burguês; para sair da lama a filha abandona os pais. A terceira parte visa à instrução e ao redirecionamento: um grupo de jovens pratica esporte e nele a filha do casal reencontra o noivo. $O$ grupo cultiva a nudez, competições esportivas e canta canções, fortalecendo a vontade de mudança e tendo ao fundo cartazes clamando pela solidariedade. Tudo isso é contrastado em diferentes conversas e declarações de pessoas com visões de mundo contrapostas. Kracauer faz uma descrição minuciosa do enredo e aproxima Kuhle Wampe a Drei von der Stempelstelle, de Eugen Thiele (1932): ${ }^{16}$ ambos mostram que "os desempregados estão sem chance" (KRACAUER, 2004e, p. 51). Segundo Kracauer, "Brecht e Ottwaldt vão além indiscutivelmente”. Só que "suas análises são confusas e suas demonstrações carecem de decisão. O resultado?" - pergunta - "O que poderia ter sido um golpe contra a produção cinematográfica deu com os burros n'água" (Ibid., p. 51-52).

Para Kracauer, a falha principal da composição do filme reside na falta de clareza com que são contrastados ambos os mundos,

\footnotetext{
15 Ver “Kuhle-Wampeverboten!” (KRACAUER, 2004, p. 51).

16 Sobreesse filme de Thiele ver "Thema: Arbeitlosigkeit" (KRACAUER, 2004, p. 35-37).
} 
ou seja, o dos desocupados e resignados pequeno-burgueses e o dos jovens desportistas cheios de esperança mostrados de forma estilizada. Pergunta:

A juventude de trabalhadores deve reprimir (verdrangen) o lado pequeno-burguês? Eu suponho que os roteiristas pensaram atingir a indiferença política ou o atraso dessas camadas por meio da representação do desprazer pequeno-burguês e quiseram glorificar na parte final a atividade comunista. Supondo que seja essa a intenção, de qualquer modo eles não conseguiram realizá-la. (Ibid., p. 51).

A razão é simples: a vida de filisteu é mostrada de modo genérico e caricato, esvaziando sua força de convencimento. Esquemática é a contraposição entre a velha e a nova geração e os textos das canções soam "retóricos". Certamente, o modo como a atividade desportiva é configurada é objeto de crítica: "já que o esporte é uma coisa da juventude de todas as tendências e não apenas sinal de convicção revolucionária" (Ibid.). Acrescenta mais adiante: "Resumindo, a terceira parte do filme possui um final apoteótico duvidoso, cujo otimismo não convence. Acredito, naturalmente, que é melhor cultivar esportes coletivamente do que se embebedar" (Ibid., p. 53). As situações são reduzidas a mero gesto decorativo. Kracauer não deixa de reconhecer o talento do diretor em certas tomadas do filme, sobretudo nos planos em que as situações sociais são caracterizadas por meio das faces dos personagens, lição que aprendeu com os russos, mas mostra-se inexperiente nas longas tomadas e as cenas de festas desportivas "são prolixas (weitschweifig) demais".

A crítica ao filme não é tão diferente assim da análise desenvolvida em De Caligari a Hitler. É inteiramente coerente com sua crítica ao romance-reportagem, como também à literatura de tendência, por não responder às exigências de caracterização épica. Kracauer não menospreza a arte engajada, basta recordar seu entusiasmo diante dos filmes de
Eisenstein e de Vertov, entre outros, ${ }^{17}$ ou do cinema experimental de vanguarda. Não é demais insistir: Kracauer não é um antivanguardista como Lukács! De qualquer modo, essa sua crítica ao Kuhle Wamp estourou como uma bomba de mal-entendidos, o que se pode verificar ao ler sua correspondência com Bloch.

\section{BLOCH CONTRA KRACAUER}

Com a transferência de Benno Reifenberg para Paris, Kracauer assume a editoria cultural do jornal Frankfurter Zeitung em Berlim, mas logo no início tornam-se evidentes as crescentes diferenças políticas de Kracauer com a direção da sucursal berlinense do jornal, particularmente com Rudolf Kirscher - aliás, diga-se de passagem, o Frankfurter Zeitung passava por uma séria crise financeira que provocou também mudanças em sua política editorial, passando a ser cada vez mais conivente com a onda nacionalista e com o nacional-socialismo em ascensão. Vários fatores internos e externos vão se agravando com a conjuntura política do país, deixando à vista de todos que a República de Weimar aproximava-se de seu fim. Nesse processo, Kracauer é de uma lucidez sem igual, mas, por outro lado, mostra-se também cada vez mais cético em relação a qualquer tipo de envolvimento político-partidário, sobretudo em relação aos comunistas, com a ascensão de Stalin, a política de coletivização etc. ${ }^{18}$ Não se deve perder de vista

17 Ver os artigos sobre O homem com a câmera de DzigaVertov ("Der Mann mit dem Kinoapparat". In: KRACAUER, S. Kleine Schriften zum Film 6-2, 2004, p. 247-251) e sobre a première de Potemkin em Frankfurt: "Die Jupterlampen brennen weiter. Zur Frankfurter Aufführung des Potemkin-Films" (KRACAUER, S. Kleine Schriften zum Film 6-1. 2004, p. 234-237).

18 Kracauer acompanhou ativamente a situação política e cultural da ex- URSS, ver, particularmente, a resenha que escreveu pouco antes do exílio, "Oktoberrevolution. Revolutionärer Realismus", sobre A revolução de outubro. História da revolução russa de Leon Trotzki, publicado no Deutsche Republik (05/03/1933). Resenha extremamente simpática, na qual faz um elogio ao realismo político do autor diferenciando-o da teoria da espontaneidade das massas de Rosa Luxemburg. Estava prevista uma continuação da resenha que não se realizou (KRACAUER, S. Schriften5-3., 1990, p. 201-205). 
esse conjunto complexo de fatores históricopolíticos, com o risco de não compreender criticamente, e com o necessário distanciamento histórico, as diferenças de opinião que vamos relatar. O desentendimento entre Kracauer e Bloch manifesta-se, pela primeira vez, depois de anos de amizade muito próxima, em uma carta de Bloch a Kracauer no final de abril de 1931. São diferenças políticas e teóricas e que vão se agravar ao longo dos anos, antecipando o estranhamento entre ambos durante o exílio parisiense, a partir de 1933. Esquematicamente, podemos dizer que um dos motivos desse distanciamento decorre da política, isto é, Bloch aproxima-se cada vez mais dos comunistas, apesar de nunca ter se filiado ao KP alemão, ao contrário de Karola Bloch, sua esposa. Se Bloch torna-se uncompagnon de route dos comunistas, como Brecht, Lukács, por seu lado, já era um "homem de partido", muito diferente da posição de Kracauer que, a partir de 1933, assume definitivamente a posição de um "exterritorial" - radical!

Na referida carta, Bloch lamenta que nos últimos dois anos observou uma mudança de convicção em Kracauer:

o homem que quer defender a cultura contra a barbárie, que toma a Grécia como comparação para a Europa Ocidental, não é mais o mesmo amante da Marselha carcomida (zerfressenten), do cinema (contra o teatro), da improvisação. (Na ocasião, você manifestara muito interesse puramente técnico, por exemplo, pelo espetáculo destrutivo e improvisador das tentativas de Brecht). (BLOCH, 1985, p. 353).

Sobre o desinteresse, ou sua recusa, em relação aos experimentos dramáticos de Brecht, e até mesmo sua oposição em publicar no Frankfurter Zeitung FZ, o ensaio de Benjamin -, Was ist das epische Theater?'19 - Bloch arremata:

9 O que é o teatro épico? não reconheço este homem, aquele que denunciava em Os empregados: "a fuga diante da revolução", não é mais o mesmo que hoje gostaria preferencialmente de viver sem revolução. [Continua Bloch.] O homem que investigou filosoficamente Marx $[\ldots]$ não é mais o mesmo que apenas vê um pouco de socialização dos meios de produção e que considera "os homens" um fenômeno eterno. (Ibid.).

Para Bloch, o crescente desinteresse de Kracauer em relação à filosofia e seu elogio à cultura só pode ser pior do que sua visão do marxismo: "Não por acaso, os revisionistas foram os primeiros a expulsar a filosofia da obra de Marx [... ] Você não se ocupa mais de teoria como antes. Sem essa não é possível nenhuma concreção" (Ibid., p. 353-354). Cita, como exemplo, seu ensaio Begegnung mit hilflosen Figuren. Der Fasching. Die Stimme, ${ }^{20}$ de fevereiro de 1931, e que foi republicado posteriormente como Berliner Figuren ${ }^{21}$ (KRACAUER, 1987, p. 109-116). A seu ver, é um erro considerar esse tipo de escrita como sendo literariamente de melhor qualidade. A mesma objeção faz Adorno posteriormente, no ensaio Der wunderlich Realist, 22 ao considerar Kracauer um "alógico" (ADORNO, 1981, p. 388-408).

A reação de Bloch ao artigo de Kracauer sobre a proibição de Kuhle Wampe é, no mínimo, curiosa, pois ele havia não ainda assistido ao filme, o que não o impede de vociferar contra o velho amigo, uma reação do tipo: não vi, mas gostei, e muito! Vale apenas transcrevermos um trecho:

O motivo é conhecido: a crítica ao filme proibido de Brecht. Nenhuma palavra sobre o filme que me é desconhecido; se ele é bom ou ruim, não está em discussão. Mas

20 Encontro com figuras desamparadas. O carnaval. Vozes.

21 Figuras berlinenses.

22 O realista curiososo. 
que você deu a conhecer um cego ódio mortal (einem blinden, hässlichen Hass) contra Brecht e ficando, sobretudo, por esse motivo, ombro a ombro com a censura (Arm in Arm mit der Zensur), num jornal cada vez mais antimarxista, o que foi para mim, pelo seu passado e pela nossa amizade, dificilmente suportável. (BLOCH, 1985, p. 357).

E acrescenta que sua atitude não passa de sentimento privado (Privatgefühle), cuja ideologia mistura-se, inconscientemente, com a coisa. Se Kracauer havia respondido à carta de abril de 1931, não sabemos, mas esta última, que data de maio de 1932, mereceu, de imediato, uma longa e turbulenta resposta.

Kracauer começa dizendo que os ataques de Bloch a seu artigo contra a proibição não precisariam partir dele, sobretudo quando o acusa de ter ficado ombro a ombro com a censura, uma afirmação cujo embasamento ele desconhece totalmente.

Ao contrário, meu protesto contra a proibição do filme foi minucioso, incisivo e mais preciso do ponto de vista do conteúdo do que todos os outros e posso supor que justamente por ter sido meu protesto exatamente motivado tenha contribuído não de modo inessencial pela suspensão da proibição. (lbid.).23

Segundo Kracauer, Bloch não levou em consideração de que modo ele uniu seu protesto contra a proibição com uma crítica ao filme; muito pelo contrário, para Bloch, essa crítica não deveria ser dirigida ao filme. Ela não passaria de mera manifestação de "um cego ódio mortal contra Brecht”, ou seja, seu juízo não é decorrente de uma questão objetiva (sachliche Angelegenheit), mas de uma mescla da coisa com sentimento privado e suas ide-

23 Depois de ter sido proibido duas vezes, Kuhle Wampe foi finalmente liberado com muitos cortes. A première do filme ocorreu em 30/05/1932. ologias (Ibid., p. 358-359). Kracauer recusa-se a responder a este tipo de acusação injusta, inteiramente contrária a seu posicionamento, uma insinuação totalmente impossível. Cita o exemplo de Tretiakov, no qual chegou a se manifestar positivamente quando este se mostrou útil e bom, o que não seria diferente com Brecht, caso este produzisse "algo apto”. E duvida que o próprio Bloch acredite nas acusações lhe dirige. Em seguida, refere-se à afirmação de Bloch, segundo a qual ele não deveria ter publicado sua crítica no Frankfurter Zeitung , como se suas manifestações críticas fossem as da direção do jornal e não as suas próprias. A crítica não foi de "uma foIha antimarxista", revida, "mas de um homem do qual a esfera pública competente sabe muito bem de onde ele fala" (Ibid., p. 359). E acrescenta: "a união de crítica com protesto foi legítima e necessária por razões muito diferentes" (Ibid., p. 360). Depois comenta a relação que Bloch estabelece entre seu passado e a amizade de ambos:

Ao meu passado: o que significa isso? Quer dizer com isso, que a luta pela transformação da sociedade atual pertence ao meu passado? Espero que não. Já me expus visivelmente e mais do que outros pelo marxismo e continuo me expondo; de um modo que corresponde ao meu talento e às minhas forças. (Ibid.).

A controvérsia continua em uma carta seguinte de Bloch a Kracauer, de início de junho de 1932, na qual Bloch retoma alguns pontos das cartas anteriores:

Caro Krac, nossa diferença de opinião (Meinungsverschiedenheit) não é de hoje. Mesmo o Tretiakov, que você menciona várias vezes, dá a essa diferença só motivo exterior [... ] A "esfera pública competente" não sabe mais "inteiramente" (ganzgenau), onde você está. 
Invertendo a frase de Kracauer. Resume:

Questão principal: sua amargura e a crítica de época que decorre dela não me parece mais da mesma maneira que antes. Essa era apátrida, desesperada, sem amargura, tinha tiradas demoníacas e, sobretudo, força explosiva (Sprengkraft). Agora é o Ressentimento (a expressão não é minha [... ] mas de leitores em Ludwighaften, Mannheim e Munique), como um professor irritado que insulta a sala de aula. (Ibid., p. 363).

Bloch insiste na aversão de Kracauer à teoria ou a repensar a relação "marxismo e filosofia": "Desse modo você rebaixa o nível do marxismo; sua aversão (Abneigung) a Hegel (os revisionistas já fizeram isso antes) pertence de qualquer modo aquil". Como se Kracauer não se ocupasse do problema da "falsa consciência", conceito que foi - salvo engano - introduzido pelo autor da Fenomenologia do espírito, o qual Kracauer em Os empregados dá uma "concreção" materialista extremamente original e "sensível”, ligada ao "mundo das coisas", ao "asilo dos sem-teto" e à "construção da falsa consciência". Na verdade, os problemas aflorados têm longa data, isto é, desde a resenha crítica escrita por Kracauer ao Thomas Münzer als Theologe der Revolution de Bloch, na qual critica sua tentativa de conciliar uma visão quiliástica com o comunismo (KRACAUER, 1990a, p. 196-204).

Apesar da truculência dos termos, Kracauer não deixa de ironizar os argumentos de Bloch na carta seguinte, de 4 de junho de 1932, dizendo que ele subestima sua "disposição de defesa" (Verteidigunglust):

defendi, e me defendo apenas contra a insinuação que no caso do artigo sobre Brecht eu tenha projetado sentimento privado na coisa. Isto vai contra a minha essência, contra minha natureza, cuja paixão (Leidenschaft) é a coisa. (BLOCH, 1985, p. 365).
E é incisivo:

Você oscila entre um lugar utópico e um marxismo prático e me acusa de não ser radical suficiente, que escrevo num falso lugar (Franfurter Zeitung-CEJM) etc. [...] Quando você em $O$ espírito da utopia expõe, caro Ernst, deveria pelo menos saber que esse livro, de certa forma, está próximo do verdadeiro comunismo apenas par hasard [...] A revolução, que você entende nesse caso, não é a que Marx tinha em mente, mas uma que nunca e em lugar algum se realizou. (Ibid., p. 366).

Sem deixar o tom provocativo e bem humorado, acrescenta: "Se Marx o tivesse conhecido, provavelmente insultá-lo-ia” em sua tentativa de projetar transcendência no marxismo, algo em que Kracauer não vê nenhum fundamento objetivo. A celeuma para por aqui. Há outra carta de 24 de setembro de 1932 particularmente interessante, na qual Bloch expõe a Kracauer sua preocupação com o agravamento da situação política alemã, particularmente depois da "fasticização da burguesia". A correspondência entre ambos segue até a morte do segundo, em dezembro de 1966, mas trata-se de cartões e bilhetes rápidos; o exílio interrompe a discussão.

\section{MetAFísico de FOLHETIM X IDEALISTA ÀS AVESSAS}

A relação de Kracauer com Brecht é, certamente, atribulada. Em novembro de 1930, Kracauer publicou um artigo sobre o processo jurídico de Brecht e Kurt Weil com a Nerofilm a respeito dos direitos autorais da filmagem de A ópera dos três vinténs ${ }^{24}$ e a continuação, com a vitória de Weil, não de Brecht, ${ }^{25}$ posicionando-se inivocamente a favor dos autores. Neste artigo, Kracauer denuncia a inescrupulosidade (Bedenkenlosigkeit) da indústria cinematográ-

24 Ver KRACAUER, 2004, p. 418-423.

25 "Ein gut ausgenutzter Sieg. Kurt Weil um die Tobis" (Ibid., p. 451-453). 
fica contra obras de categoria e cita, além de Brecht e Weil, Ilia Ehrenburg, Die Liebe der Jeanne Ney (O amor de Jeanne Ney), a filmagem da peça de Georg Kaiser, Zwei Kravatten (Duas gravatas), situação que se agravou sobretudo com o cinema falado, nos quais as obras literárias são simplesmente saqueadas, obedecendo a cínicos interesses comerciais imediatos. Não vou reproduzir detalhadamente os argumentos do texto. Já sabemos da batalha levada a cabo por Kracauer nesses anos contra os grandes estúdios cinematográficos; batalha que colocou em risco seu emprego no Frankfurter Zeitung, que passava por uma grave situação financeira e assumindo posições cada vez mais à direita, para não falar de uma lenta fasticização. ${ }^{26} \mathrm{~A}$ questão é que o artigo sobre o processo jurídico em torno do filme "A ópera dos três vinténs" não é levado em consideração por Brecht na discussão que passamos a narrar.

Em 1932, ou seja, dois anos depois, Brecht publica um dos volumes de seus ensaios que contém um tratado sobre o referido processo; nele propõe um "experimento sociológico" (soziologisches Experiment), que seria "um novo método crítico". Kracauer, como veremos, escreve uma resenha cáustica afirmando que Brecht faz um uso falso de seus artigos, ou seja, cita sem nominá-lo, e que não leu seu balanço sobre a produção cinematográfica alemã do período (Film 1928) (KRACAUER, 1977, p. 295-310). Já vimos que Kracauer sai na defesa do Kuhle Wampe, com roteiro de Brecht e Ottwalt, quando este foi proibido pela censura, mas é crítico em relação ao esquematismo da "mensagem" do filme, quase nos mesmos termos que posteriormente expressa em seu De Caligari a Hitler, "são jovens atletas no festival comunista de esporte", um filme "que glorifica a vida coletiva". Vou tentar reconstruir seus argumentos, mais adiante, que, para mim, desmentem a insinuação de Bloch, segundo a qual Kracauer

26 Para se ter uma ideia, em 1929, a I.G. Farben comprou 49\% das ações da Frankfurter Societäts-Drückerei. Para uma visão conjunta, ver GILLESSEN, 1986, apud MÜLDER-BACH, 2006, p. 384. estaria possuído por um "ódio mortal" contra Brecht. A questão é, ao mesmo tempo, política e estética, e não de caráter pessoal.

Brecht no seu ensaio citado sobre o Dreigroschen-Prozess começa com a intenção de obter justiça e interpreta, posteriormente, como um desafio que pudesse servir para tornar visível o jogo das forças sociais, sendo um aprendizado - daí o sentido de "experimento sociológico". Nas palavras de Brecht: “Que por meio de um ato seja capaz de produzir reações incisivas contra uma injustiça insuportável, tornando-se, portanto, um avanço planejado, o qual toma a injustiça como seu próprio objeto" (BRECHT, 1992, p. 448). O ensaio é longo, com mais de 60 páginas; destaco apenas o trecho no qual Brecht cita quase uma página inteira do artigo de Kracauer de 18 de abril de 1991, Asta Nielsen und die Filmbranche ${ }^{27}$ (KRACAUER, 2004c, p. 482-486). "3. Man kann den Publikumsgeschmack verbessern" [Pode-se melhorar o gosto do público]. Artigo, diga-se de passagem, que não tem nada a haver com o processo judicial em questão. Brecht considera os argumentos de Kracauer uma "discussão metafísica". O artigo é uma defesa da grande atriz Asta Nielsen, que se torna esquecida dos grandes estúdios, fato que Brecht não releva. Como um grande provocador, ele diz que "nosso metafísico de folhetim" (p. 471) estaria interessado em melhorar o gosto do público. Kracauer, em momento algum, refere-se a isso e jamais propôs algo, no mínimo, tão ingênuo do tipo, sobretudo em se tratando de um crítico rigoroso que sabe muito bem das tarefas do crítico de cinema, isto é, que "na economia capitalista o filme é uma mercadoria como outras mercadorias [...] O grosso da produção tem por fim simplesmente o entretenimento elevado ou a distração barata" (Ibid., p. 61, 62). Em suma: "um crítico de cinema digno desse nome só é concebível como crítico da sociedade". Para Brecht,

a falta de gosto das massas está mais profundamente enraizada na realidade do que o gosto dos inte-

27 Asta Nielsen e o ramo cinematográfico. 
lectuais [...]. A representação do folhetinista é inacessível: pode-se mudar o gosto do público não por meio de filmes melhores, mas apenas por meio da mudança de sua relação. (BRECHT, 1992, p. 473).

Sabemos que a argumentação de Kracauer vai em outra direção e que sua crítica à produção cinematográfica alemã do período pauta-se na falta de substância de suas realizações, por sua irrealidade, por seu ímpeto evasivo etc. Jamais assumindo uma posição elitista ou de cunho estetizante, muito pelo contrário, para ele, quanto pior o filme meIhor para se poder evidenciar as tendências ideológicas em jogo na sociedade. Brecht é extremamente injusto. Na sequência, como não poderia deixar de ser, cita Thomas Mann, alvo preferido de seus ataques nesses anos:

sua representação oculta a representação de que o cinema deveria ser pequeno-burguês (spiessbürgerlich). A generalidade desta tendência tão "sensata" [...] é produzida por meio de uma exigência implacável de que a arte deveria ser "aprofundada", segundo o referido metafísico da imprensa [...] por isso esbravejam pelo "como" e não pelo "o que", revelando assim o pequeno-burguês. Mas, em se tratando apenas do "como", nada mais é propriamente do que pequeno-burguês. (Ibid., p. 476-477).

Como se apelassem para um "destino" imutável do "humano" e que "Chaplin sabe muito bem que o ‘humano' nada mais é do que pequeno-burguês", referindo-se ao plano final de Luzes da cidade. Uma posição implacável nem sempre dada ao diálogo - sectária. Passemos, para finalizar, aos argumentos também implacáveis de Kracauer, só que este não chama Brecht de "pequeno-burguês" ou de "metafísico", mas de "idealista" - o que para um marxista não soa, certamente, como um elogio.
A irritação de Kracauer parte do fato de que Brecht, ao invés de referir-se ao artigo que escreveu a propósito do processo judicial sobre a filmagem da Ópera dos três vinténs, faz uso de outro, já citado, de maneira inteiramente falsa, como se fosse "um contrabando de citações" (Zitatschmuggel), sendo, portanto, "não metódico" e "não científico". Para ele, Brecht agiu de modo "não dialético". Como ele mesmo resume:

Brecht aqui como alhures não analisa a situação, mas apenas age contra ela. A análise de uma situação ajuda a transformá-la; uma tal bazófia (Blague) não produz transformação alguma [...]. Uma paixão romântica pelo concreto que nada mais é do que um idealismo invertido. (KRACAUER, 199ob, p. 36-37).28

Faltaria uma análise mais detida e que Brecht desconhece seus ensaios como Film und Gesellschaft. ${ }^{29}$ Pequenas balconistas vão ao cinema" ou o estudos de Béla Baláz Der Geist des Films [O espírito do cinema], afirmando, "Brecht evidentemente não leu nada disso", e - sem deixar de ser também um bom provocador - faz referência, não mais e nem menos, ao livro de Lukács, História e consciência de classe, segundo ele, elucidativo para a "compreensão do valor de uso social da sentimentalidade" (KRACAUER, 199ob, p. 36-37).

Parece, à primeira vista, que nos deparamos, não só com diferenças de opinião irreconciliáveis, como também de uma quase inimizade. Mas não é bem assim. Eles chegaram, não só a se encontrar pessoalmente - Kracauer chega a dizer que era incapaz de ser dialético nas conversas -, como também a participar de debates públicos, certamente sempre mediados pela presença de Walter Benjamin, que nutria uma enorme simpatia por Brecht; basta ler a correspondência entre

\footnotetext{
28 "Ein soziologisches Experiment."

29 Publicado posteriormente com o título "Pequenas balconistas vão ao cinema" (In: KRACAUER, 1977, p. 279-294).
} 
Kracauer e Adorno para dissipar essa impressão, pois, naqueles anos (1931) de final da República de Weimar, Brecht e Walter Benjamin tinham em mente organizar uma revista, Krisis und Kritik, e convidaram, tanto Kracauer como o jovem Adorno para participar como colaboradores, mas o projeto, por razões políticas óbvias, não foi em frente. ${ }^{30}$

\section{UM PROJETO DE REVISTA}

Sobre esse projeto de revista vale abrir um breve parêntese. Já vimos que a revista berlinense Die Linkskurve começou a ser publicada em agosto de 1929 e havia, no contexto, toda uma discussão em torno do papel do escritor ou do artista em geral, como também em como pensar a função da arte, a relação entre arte e sociedade, as novas técnicas etc. Entre setembro de 1930 e junho de 1931, Benjamin e Brecht pretendiam publicar uma revista com a editora Rowohlt de Berlim, juntamente com Bernahard von Bretano e Herbert Ihering e com a colaboração de Ernst Bloch, Siegfried Kracauer, Alfred Kurella e Georg Lukács. O projeto se pretendia amplo e abrangente, claramente de esquerda, mas sem vínculos partidários, mesmo que incluísse até comunistas, como Kurella e Lukács, uma frente de intelectuais. Como se pode ler no memorando escrito por Benjamin em torno de outubro/novembro de 1930: "Ela [a revista] tem um caráter político, sua atividade crítica está ancorada numa consciência clara da crítica situação de fundo da sociedade atual. Ela se coloca no chão da luta de classes". ${ }^{31}$ Além daqueles diretamente envolvidos com o projeto, pode-se acrescentar também o nome

30 Trata-se de uma longa carta de 02/01/1931 de Adorno a Kracauer, na qual o primeiro indaga ao segundo sobre sua opinião a propósito do projeto da revista (ver ADORNO, 2008, p. 258-59).

31 "Memorandum zu der Zeitschrift "Krisis und Kritik" (In: BENJAMIN, 1985, p. 619-621). Benjamin arrola em sentido provisório alguns colaboradores: "Benjamin, Hans Borchart, Behne, Bretano, Brecht, Döblin, Dudow, Eisler, Franzen, Gideon, Gross, Hindemith, Ihering, Kracauer, Kurella, Herman Kantowicz, Lukácz [sic], Hannes Meyer, Marcuse, Musil, Piscator, Reger, Reich, Sternberg, Weil, Wiesengrund [Adorno]" ( $p$. 619-620). de escritores como Alfred Döblin, Albert Ehrenstein, Robert Musil, Hans Stahl e Peter Suhrkamp; os diretores de teatro Stalam Dudow, Erwin Piscator; os compositores e teóricos da música T. W. Adorno, Hanns Eisler, P. Hindemith e Kurt Weill; os teóricos da arte e da arquitetura Adolf Behne, Siegfried Gideon e Hannes Meyer, assim como Georg Grosz, o historiador Arthur Rosenberg, o filósofo Karl Krosch e o psicólogo Wilhelm Reich, entre outros. Um projeto extremamente ambicioso, instigante e inovador. Aqui, basta a referência histórica, pois esse projeto fracassado da revista já foi analisado minuciosamente bem e com rigor por Erdmut Wizisla em Crisis e crítica, documentando, até, com atas das discussões entre seus membros, com a participação, além de Brecht e Benjamin, Kracauer e Bloch, entre outros (WIZISLA, 2004). Segundo o atual diretor do Arquivo Bertolt Brecht e do Arquivo Walter Benjamin em Berlim,

o fracasso do projeto da revista teve sua raiz na falta de unidade dos intelectuais de esquerda [...] "A intenção dos artistas e especialistas de imiscuir-se com seu próprio trabalho nos interesses de seu entorno sem perder por um lado a medida e a capacidade de discernimento, não pode se realizar. No entanto, seu fracasso não prova que a aspiração de Krisis und Kritik tenha sido ilusória (p. 165). 


\section{REFERÊNCIAS}

ADORNO, T. Noten zur Literatur. Frankfurt am Main: Suhrkamp, 1981.

BENJAMIN, W. Gesammelte Schriften. Band VI. Frankfurt am Main: Suhrkamp, 1985.

BLOCH, E. Briefe. Band I. Frankfurt am Main: Suhrkamp, 1985.

BRECHT, B. Der Dreigroschenprozess. Ein soziologisches Experiment. In: Schriften 1. Frankfurt am Main: Suhrkamp, 1992.

GALLAS, H. Teoría marxista de la literatura. Buenos Aires: Siglo Veintiuno, 1973.

GILLESSEN, G. Auf verlorenen Posten. Die Frankfurter Zeitung im Dritten Reich. Berlin: Siedler, 1986.

KRACAUER, S. Die Angestellten. Frankfurt am Main: Suhrkamp, 1971.

. Die Photographie. In: . Das Ornament der Masse. Frankfurt am Main: Suhrkamp, 1977. . Strassen in Berlin und anderswo. Berlin: Das Arsenal, 1987.

. Prophetentum. In: Schriften 5-1. Frankfurt am Main: Suhrkamp, 1990a.

. Schriften 5-3. Frankfurt am Main: Suhrkamp, 1990 .

. Der Mann mit dem Kino-Apparat. In: KRACAUER, S. Kleine Schriften zum Film 6-2. Frankfurt am Main: Suhrkamp, 2004 a.

. Der Prozess um die Dreigroschenoper. Einigenachträgliche Randbemerkungen. In: Kleine Schriften zum Film. Werke 6-2. Frankfurt am Main: Suhrkamp, 2004b.

. Die Jupterlampen brennen weiter. Zur Frankfurter Aufführung des Potemkin-Films. In: Kleine Schriften zum Film 6-1. Frankfurt am Main: Suhrkamp, 2004C.

. Ein gut ausgenutzterSieg. Kurt Weil um die Tobis In: Kleine Schriften zum Film. Werke 6-2. Frankfurt am Main: Suhrkamp, 2004d.

2004 e.

. Kuhle Wampe verboten! In: Kleine Schriften zum Film. 6.3. Frankfurt am Main: Suhrkamp,

. O ornamento da massa. Trad. Carlos Eduardo Jordão Machado e Marlene Holzhausen. São Paulo: Cosac Naify, 2007.

LÖWY, M. György Lukács. Littérature, philosophie, marxisme (1922-1923). Paris: PUF, 1978.

LUKÁCS, G. Reportage oder Gestaltung. In: KLEIN, A. Georg Lukács in Berlin. Berlin: Aufbau, 1990. MACHADO, C. E. J. As formas e a vida. São Paulo: Unesp, 2004.

VEDDA, M. (Orgs.). Siegfried Kracauer. Un pensador más allá de las fronteras. Buenos Aires: Gorla, 2010.

. Um capítulo da história da modernidade estética. Debate sobre o expressionismo. São Paulo: Unesp, 1998.

; CIORDIA, M. J.; VEDDA, M. (Orgs.). Filosofias provisórias. Reflexiones en torno a ensayos y ensaystas. Buenos Aires: Gorla, 2012.

MÜLDER-BACH, I. Nachbemerkung und editorische Notiz. In: KRACAUER, S. Werke. Band 1. Frankfurt am Main: Suhrkamp, 2006. 
MÜLDER-BACH, I. Siegfried Kracauer.Grenzgänger zwischen Theorie und Literatur: Seine früehen Schriften 1913-1933. Stuttgart: Metzler, 1985. 2004. . Thema: Arbeitlosigkeit. In: KRACAUER, S. Schriften 6-3. Frankfurt am Main: Suhrkamp,

TROTZKI, L. Oktoberrevolution. Revolutionärer Realismus. Deutsche Republik, 05-03-1933.

WIZISLA, E. Benjamin und Brecht. Die Geschichte einer Frendschaft. Mit einer Chronik und den Gesprächsprotokollen des Zeitschriftenprojets "Krise und Kritik". Frankfurt am Main: Suhrkamp, 2004.

DADOS DO AUTOR:

CARLOS EdUARDo Jordão MACHAdo

Professor de História da Filosofia e da Arte na Unesp, Campus de Assis, SP

Recebido: 09/04/2013

Aprovado: 03/06/2013 
